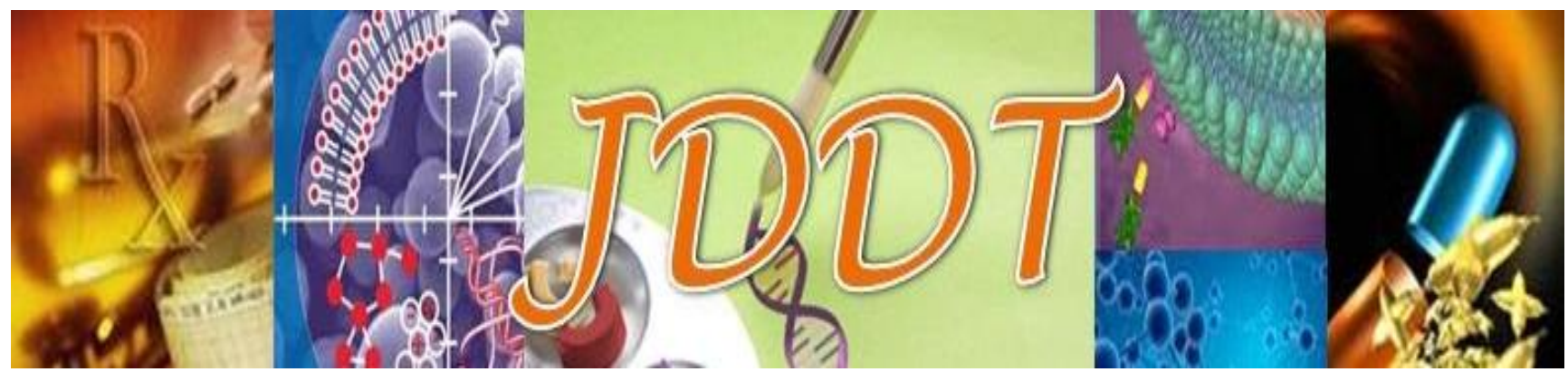

\title{
Editor Massage
}

The Journal of Drug Delivery \& Therapeutics (JDDT) is an international Pharmaceutical journal launching on September 2011 and will be issued Bi-monthly. JDDT is a platform established with the aim of motivating the students and researchers in the field of Pharmaceutical Research and Development. JDDT publishes Reviews and Original Research articles related to Pharmaceutical science. JDDT aims to publish all the original research in the field of science so a correlation can be made between these researches.

JDDT started with an intention to publish rapid research in the fields of pharmacy. JDDT provides free access to all articles published without any barriers to the scientific community. Currently, we invite most exciting researches in the areas of pharmacy. Authors are requested to access journal home page for a complete list of aims and scope of the JDDT. We are primed to provide a rapid turnaround time of the articles submitted to JDDT. However, all submissions are peer-reviewed and the expert reviewers are invited to join the team.

Hence, JDDT call the eminent personalities in respective fields of Pharmaceutical science to strengthen our journals by joining in editorial board and publish their valuable work with JDDT. At the same time, I welcome opinions and comments to improve the editorial policy of the JDDT.

I am highly obliged and convey most sincere gratitude and kindest regards to authors, reviewers and editorial board members. I hope you find this journal informative and useful. It is a new initiative. Your valuable comments and suggestions will help us improve the quality and content of the journal. I hope by cooperation and blessing of all authors, reviewers and editorial members, JDDT will be useful for pharmaceutical researchers.

With warm regards:

R C Dhakar, Editor in Chief

Journal of Drug Delivery \& Therapeutics (JDDT)

editor.jddt@gmail.com

http://jddtonline.info/ 